\title{
Correction to: Phase I-II trial of imatinib mesylate (Gleevec; STI571) in treatment of recurrent oligodendroglioma and mixed oligoastrocytoma. North central cancer treatment group study N0272 (ALLIANCE/NCCTG)
}

Kurt A. Jaeckle ${ }^{1}(1)$. S. K. Anderson ${ }^{2} \cdot$ Erin L. Twohy $^{2} \cdot$ Jesse G. Dixon $^{2} \cdot$ Caterina Giannini $^{3} \cdot$ Robert Jenkins $^{3}$. Merrill J. Egorin ${ }^{4}$. Jann N. Sarkaria ${ }^{3}$. Paul D. Brown ${ }^{3}$. P. J. Flynn ${ }^{5}$. John Schwerkoske ${ }^{5}$. Jan C. Buckner ${ }^{3}$. Evanthia Galanis ${ }^{3}$

Published online: 5 June 2019

(c) Springer Science+Business Media, LLC, part of Springer Nature 2019

Correction to: Journal of Neuro-Oncology

https://doi.org/10.1007/s11060-019-03194-z

The last author's first name was truncated in the initial online publication. The original article has been corrected.

Publisher's Note Springer Nature remains neutral with regard to jurisdictional claims in published maps and institutional affiliations.

Merrill J. Egorin-Deceased

The original article can be found online at https://doi.org/10.1007/ s11060-019-03194-z.

Kurt A. Jaeckle

jaeckle.kurt@mayo.edu

1 Mayo Clinic Florida, 4500 San Pablo Road, Jacksonville,

FL 32224, USA

2 Alliance Statistics and Data Center, Mayo Clinic, Rochester, MN, USA

3 Mayo Clinic Rochester, Rochester, MN, USA

4 University of Pittsburgh, Pittsburgh, PA, USA

5 Metro-Minnesota, St. Louis Park, MN, USA 